\title{
Pre-service Physics Teachers' Opinions about the Difficulties in Understanding Introductory Quantum Physics Topics
}

\author{
Hasan Şahin Kızılcık ${ }^{1}$, Pervin Ünlü Yavaş² \\ ${ }^{1}$ Gazi Faculty of Education, Gazi University, Ankara, Turkey \\ ${ }^{2}$ Gazi Faculty of Education, Physics Education Department, Ankara, Turkey \\ Correspondence: Pervin Ünlü Yavaş, Gazi Faculty of Education, Physics Education Department, Ankara, Turkey.
}

Received: November 25, 2016

Accepted: December 12, 2016 Online Published: December 14, 2016

doi:10.11114/jets.v5i1.2012

URL: http://dx.doi.org/10.11114/jets.v5i1.2012

\begin{abstract}
The aim of this study is to identify the opinions of pre-service physics teachers about the difficulties in introductory quantum physics topics. In this study conducted with twenty-five pre-service physics teachers, the case study method was used. The participants were interviewed about introductory quantum physics topics. The interviews were coded using content analysis and were divided into different categories. In this way, we tried to reveal the opinions of pre-service physics teachers about the difficulties of these topics. In conclusion, it can be said that the participants had the most difficulty in transition from classical physics to quantum physics. This is especially evident in quantum physics topics that require a different understanding such as black body radiation, wave-particle structure of light and the uncertainty principle. It was also found that the participants had no difficulties in terms of mathematical calculations, and that approaches based on visualizing the topic were received positively.
\end{abstract}

Keywords: introduction to quantum physics, teacher training, learner's opinions, difficulty in understanding

\section{Introduction}

Quantum theory explains the general behaviours and interactions of atoms, nuclei and elementary particles. In addition, quantum theory consists of the most basic laws of nature since it applies to both the sub-microscopic and macroscopic worlds. Although these laws attract little attention from most people, they explain facts that directly affect our life and are used in areas such as computing, laser technology and nuclear energy. For this reason, the teaching of quantum physics, which has a history of over one hundred years, is quite important. Previously only taught in higher education, in recent years quantum physics is also taught in high schools. Since 2008, the teaching of quantum physics has been given more and more importance at the high school level. Rather than the mathematical formulation of quantum mechanics, introductory quantum physics topics are given greater importance at this level. Therefore, the study conducted with pre-service physics teachers was limited to these topics and this paper only addresses the related literature.

The number of studies on difficulties experienced by students in understanding the quantum physics topics is relatively low compared to other physics education studies (McDermott \& Redish, 1999). However, the number of such studies has increased in recent years. Studies related to the uncertainty principle have an important place among these studies (Akarsu, Coşkun \& Karpier, 2011; Ayene, Kriek \& Damtie, 2011; Johansson \& Milstead, 2008; Özdemir \& Erol, 2011; Pospiech, 2000; Y1ld1z \& Büyükkasap, 2011). In a study, in which university students were asked to describe quantum physics, it was found that students considered the Heisenberg's Uncertainty Principle as the most important topic in quantum physics (Didiş, Özcan \& Abak, 2008). The photoelectric effect is another such quantum physics topic (Fletcher \& Johnston, 1999; De Leone \& Oberem, 2004; Steinberg, Oberem \& McDermott, 1996).

In general, quantum physics is difficult to understand and misunderstandings and misconceptions are common among students. The students' conceptual understanding of the quantum physis has been researched (Ireson, 1999; Mannila, Koponen \& Niskanen, 2002). Şen (2002) studied the misconceptions that university students have about the concepts of quantum physics. Another study investigating the conceptual meanings of quantum physics was carried out by pre-service science teachers (Baybars \& Küçüközer, 2014). Students' models of microscopic processes in the context of modern physics experiments have been explored (Thacker, 2003). 
Studies have been conducted on the teaching and learning of quantum physics, which is often considered difficult by students. Abhang (2005) has presented ideas for students to easily learn the quantum physics. In another study, historical debates have been used in the teaching of quantum physics. Some methods have been proposed to overcome the difficulties and misconceptions about quantum physics. Interactive learning tutorials (Singh, 2008; Steinberg et. al., 1996), Visual Quantum Mechanics materials (Zollman, Rebello \& Hogg, 2002), a hybrid learning model (Özdemir \& Erol, 2011), and materials that combine hands-on activities and computer visualization (Rebello \& Zollman, 1999) were developed. Virtual laboratories (Müller \& Weisner, 2002) and computer simulations (Henriksen, Berit Bungum, Angell, Tellefsen, Frågåt \& Bøe, 2014) were also used and their positive contributions were reported.

In studies that investigated the difficulties of students related to quantum physics, difficulties were directly or indirectly identified based on students' answers to quantum-mechanics-related questions and observations. Although there are several studies in the literature dealing with difficulties experienced by students in physics (Angell, Guttersrud \& Henriksen, 2004; Ornek, Robinson \& Haugan, 2007; Şahin \& Yağbasan, 2012), there is no study that investigates the reasons given by students for quantum physics-related difficulties experienced by them. Therefore, this study differs from other studies in that it investigates the reasons for student difficulties in quantum physics topics through learners' opinion. The aim of the study is to identify opinions of pre-service physics teachers about difficulties experienced in introductory quantum physics topics.

\section{Method}

This study was conducted using the case study method, which is one of the qualitative research methods. The reason for using qualitative research methods in the study is because it was intended to achieve analytic generalizations rather than generalizing the results for the population. Analytical generalizations aim to reach certain conclusions or develop theories through a limited number of participants or information sources (Altunışık, Coşkun, Yıldırım \& Bayraktaroğlu, 2002). The case study is defined as an "in-depth review focusing on a current case, event, situation or set" (Yin, 1984). In other words, the case study is an in-depth study seeking answers for "what", "how" and "why" questions (Bayık, 2010). A case study involves in arriving at an interest towards the process rather than the results, the context rather than a specific variable, and reviewing and finding rather than proving (Merriam, 1998). For these reasons, the case study method was used in the study.

The study was performed during a course in which introductory quantum physics was taught. The subject of introductory quantum physics was taught by dividing it into topics of Black Body Radiation, Photoelectric Effect, Compton Effect, Atomic Spectra, Bohr's Atom Model, Wave and Particle Properties of Light, Wave Properties of Particles, Double-slit Experiment with Electrons and the Uncertainly Principle.

\subsection{Participant Selection}

This study, in which the difficulties of pre-service physics teachers were investigated, was carried out with students taking an Introductory Quantum Physics course. The study was conducted during the Spring Semester of 2014 with 25 pre-service physics teachers. Pre-service physics teachers take this course in the $6^{\text {th }}$ semester. In the semester in which this study was conducted, three (two female \& one male) participants were in the $6^{\text {th }}$ semester of their university education, nine (seven female \& two male) participants were in the $8^{\text {th }}$ semester, nine (six female $\&$ three male) participants were in the $10^{\text {th }}$ semester, four (two female \& two male) participants were in the $12^{\text {th }}$ semester or above. The high number of pre-service teachers repeating the course, which was supposed to be taken in the $6^{\text {th }}$ semester, can be seen as an indicator of their difficulties in this course. The aim of this study is to identify these difficulties. Therefore, purposive sampling was preferred and volunteer students taking the course in the related semester were included in the study.

\subsection{Data Collection Method}

Data collection was carried out in two stages. In the first stage, the participants were asked to write down their opinions regarding their difficulties about understanding quantum physics subjects on the prepared form. The form in question was designed in an open-ended manner allowing participants to write their opinions about each of the nine subjects separately. The participants wrote their opinions about each of the subjects in the field allocated for each specific subject. There was no time limit at this stage. The form filling process took 15 minutes at least, 30 minutes at the most and 20.3 minutes on average.

In the second stage, unstructured interviews were conducted with the participants to further investigate their opinions about difficulties in order to better understand their statements. During these interviews, the statements made by the participants in the forms were taken as the reference point and open-ended questions were asked depending on the participant. Some participants changed or made additions to some of their statements and explained them in detail. Thus, an attempt was made to find out the opinions of the participants more clearly and deeply. There was no time limit for 
the interviews either. The interviews took 10 minutes at least, 50 minutes at the most and 20.9 minutes on average.

\subsection{Data Analysis Method}

The description forms and interview notes, which are qualitative data sources, were combined and used as the source of raw data. Thus, a single data document was obtained from two data sources. The data was evaluated using the content analysis method. The main purpose of the content analysis is to find the concepts and relations that explain the data in hand (Yıldırım \& Şimşek, 2006). The content analysis method was used in order to identify the data, to bring the similar data together within the framework of certain concepts and themes and reveal the thoughts that might be hidden in the data (Aslan, 2009; Kızılcık, Damlı \& Ünsal, 2014). To this end, the raw data was encoded and grouped. The said codes were divided into categories and grouped together using their similar features. The principle of "coding according to concepts concluded from the data", which was suggested by Strauss and Corbin (1990), was used for coding. The codes were divided into eight categories in total. These categories are shown in Table 1 with examples. The examples given in Table 1 were taken from documents created by combining the statements of the participants written in the forms or used during interviews as a description for that category. The participants were numbered from A1 to A25.

Table 1. Categories and descriptions

\begin{tabular}{|c|c|c|}
\hline Category & Description & Examples \\
\hline $\mathrm{C} 1$ & $\begin{array}{l}\text { Difficulties in problem solving, related to } \\
\text { formulas, in unit conversion, related to using } \\
\text { graphics, and other difficulties related to } \\
\text { mathematical competence. }\end{array}$ & $\begin{array}{l}\text { A8: "It is very easy to solve (Uncertainly Principle) problems." } \\
\text { A9: "It takes a lot of effort to generate (Compton Effect) formulas." } \\
\text { A15: "(Atomic Spectra) is very easy (topic) because it is possible to } \\
\text { understand with single formula." }\end{array}$ \\
\hline $\mathrm{C} 2$ & $\begin{array}{l}\text { Giving examples from everyday life, using } \\
\text { thought experiments, watching } \\
\text { documentaries/animations/videos, lecturing in } \\
\text { chronological order, explaining through } \\
\text { experiments, modelling and other } \\
\text { instructional methods. }\end{array}$ & $\begin{array}{l}\text { A1: "... we have done the experiment as well. It was easier to } \\
\text { understand because it (Atomic Spectra) is a visual topic." } \\
\text { A11: "We have done the experiment on Atomic Spectra as well, so I } \\
\text { didn't have any difficulties." } \\
\text { A20: "I understood it better thanks to the video on the topic } \\
\text { (Double-slit Experiment with Electrons) that we watched." }\end{array}$ \\
\hline $\mathrm{C} 3$ & $\begin{array}{l}\text { Bias, interest/liking towards the topic, } \\
\text { caring/not caring for the topic, contradiction } \\
\text { to common sense/anticipations, exam and } \\
\text { grade anxiety, acceptance. }\end{array}$ & $\begin{array}{l}\text { A16: "It doesn't sound weird to me that the matter has wave } \\
\text { properties as well." } \\
\text { A17: "I'm biased against (Compton Effect) problems, I panic." } \\
\text { A22: “...I loved these topics (Wave Properties of Particle, } \\
\text { Double-slit Experiment with Electrons, Uncertainly Principle)." }\end{array}$ \\
\hline $\mathrm{C} 4$ & $\begin{array}{l}\text { Difficulties related to transition from classical } \\
\text { physics to modern physics, difficulties from } \\
\text { classical physics, difficulties related to } \\
\text { changes in definitions of some concepts. }\end{array}$ & $\begin{array}{l}\text { A4: "I have difficulties with the part about not being able to explain } \\
\text { Black Body Radiation with classic physics laws." } \\
\text { A12: "It is difficult to understand why Rayleigh-Jeans' study is } \\
\text { invalid for short wavelengths." } \\
\text { A18: "It is hard to accept and imagine this change in measurement } \\
\text { concept (Uncertainly Principle)." }\end{array}$ \\
\hline C5 & $\begin{array}{l}\text { Difficulties in associating the topics of } \\
\text { modern physics with each other. }\end{array}$ & $\begin{array}{l}\text { A7: "Having understood wave-particle nature of particles, I can } \\
\text { understand this (Double-slit Experiment with Electrons) too." } \\
\text { A12: "Wave Properties of Particles is easier to understand once you } \\
\text { understand the dual nature of light." } \\
\text { A19: "I understood this topic (Atomic Spectra) better once I found } \\
\text { out Bohr's solution." }\end{array}$ \\
\hline C6 & $\begin{array}{l}\text { Difficulties related to requiring effort, } \\
\text { studying and extra time to understand, } \\
\text { difficulties related to memorising, whether the } \\
\text { student took the class before or not. }\end{array}$ & $\begin{array}{l}\text { A2: "... there are several concepts and you have to memorize } \\
\text { them." } \\
\text { A6: "I wasn't able to understand for the first time. It is possible to } \\
\text { understand it when you study." } \\
\text { A7: "It (Photoelectric Effect) is easy once you understand the how it } \\
\text { functions..." }\end{array}$ \\
\hline $\mathrm{C} 7$ & $\begin{array}{l}\text { Difficulties related to concreteness and } \\
\text { abstractness of the concepts involved. }\end{array}$ & $\begin{array}{l}\text { A8: "I doesn't make sense to me that the light has two properties at } \\
\text { the same time and it's not possible to see it with naked eye." } \\
\text { A21: "...because these (Wave and Particle Properties of Light) are } \\
\text { abstract concepts..." }\end{array}$ \\
\hline $\mathrm{C} 8$ & Other topic-specific expressions & $\begin{array}{l}\text { A3: "It is hard to imagine a particle without mass." } \\
\text { A10: "Something that we know as a particle becomes a wave all of } \\
\text { a sudden, it is difficult to imagine that." } \\
\text { A22: "I didn't understand why the black body absorbs energy and } \\
\text { radiates." }\end{array}$ \\
\hline
\end{tabular}

Codes, categories and topics of introductory quantum physics were comparatively evaluated and an attempt was made to identify the opinions of participants about their difficulties. 


\subsection{Validity and Reliability}

According to Lincoln and Guba (1985), it is more appropriate to use the concepts of credibility instead of internal validity, transferability instead of external validity, dependability instead of internal reliability and conformability instead of external reliability in qualitative studies.

In order to increase the credibility, the data were diversified. For this reason, in addition to the forms, interviews were conducted with the participants. Purposive sampling was used in order to increase the transferability of the study. Also, the validity of the data obtained from the participants was improved by quoting the participants directly. The data obtained from the participants using different data collection tools was often compared and tested for consistency while creating data documents. In the same way, the consistency of comments was also tested. The results found were often compared with the data in an attempt to improve confirmability. First, the coding was undertaken separately by the two researchers conducting the study. Then, the researchers compared their codes and discussed until a consensus was reached. Thus, a rapport between the researchers was built.

\section{Results}

Some of the codes obtained via data analysis were positive and some were negative. For example; codes indicating that the student had no difficulties or codes that explain the reasons that make the subject easier to learn were considered to be "positive". On the other hand, codes indicating that the students had difficulties and explaining the reasons that make the subject difficult to understand were considered to be "negative". These codes and categories were evaluated both separately for each topic and as a whole. The number of code types and the distribution of categories according to the topics are given in Table 2.

Table 2. The number of code types and the distribution of categories according to the topics

\begin{tabular}{llcc}
\hline Topics & $\begin{array}{c}\text { Number of } \\
\text { Code Types }\end{array}$ & $\begin{array}{c}\text { Number of } \\
\text { Categories }\end{array}$ & Categories \\
\hline Black Body Radiation & $26(10+16)$ & 7 & C1, C2, C3, C4, C6, C7, C8 \\
Photoelectric Effect & $18(9+9)$ & 7 & C1, C2, C3, C4, C5, C6, C8 \\
Compton Effect & $15(4+11)$ & 5 & C1, C2, C3, C5, C6 \\
Atomic Spectra & $22(10+12)$ & 7 & C1, C2, C3, C5, C6, C7, C8 \\
Bohr's Atom Model & $16(6+10)$ & 6 & $\mathrm{C} 1, \mathrm{C} 2, \mathrm{C} 4, \mathrm{C} 5, \mathrm{C} 6, \mathrm{C} 8$ \\
Wave and Particle Properties of Light & $25(11+14)$ & 7 & $\mathrm{C} 1, \mathrm{C} 2, \mathrm{C} 3, \mathrm{C} 4, \mathrm{C} 6, \mathrm{C} 7, \mathrm{C} 8$ \\
Wave Properties of Particles & $22(10+12)$ & 8 & $\mathrm{C} 1, \mathrm{C} 2, \mathrm{C} 3, \mathrm{C} 4, \mathrm{C} 5, \mathrm{C} 6, \mathrm{C} 7, \mathrm{C} 8$ \\
Double-slit Experiment with Electrons & $18(5+13)$ & 7 & $\mathrm{C} 2, \mathrm{C} 3, \mathrm{C} 4, \mathrm{C} 5, \mathrm{C} 6, \mathrm{C} 7, \mathrm{C} 8$ \\
Uncertainly Principle & $23(11+12)$ & 6 & $\mathrm{C} 1, \mathrm{C} 2, \mathrm{C} 3, \mathrm{C} 4, \mathrm{C} 6, \mathrm{C} 7$ \\
\hline
\end{tabular}

As seen in Table 2, a minimum of 15 and a maximum of 26 code types were determined in the topics. The minimum number of code types were in the Compton Effect topic and the maximum number of code types were in the Wave and Particle Properties of Light topic. The numbers shown in parentheses in the code number column indicate the number of "positive" \& "negative" codes. Proportionately, the Photoelectric Effect topic had the highest number of code types, while the Compton Effect had the lowest number of code types.

When the codes were divided into categories, the codes belonging to the Compton Effect accumulated in the least number of categories (5). The codes belonging to the Wave Properties of Particles topic accumulated in the highest number of categories (8). Categories seen in all topics were C2 and C6 while C5 and C7 were the least common categories.

The frequency of codes was grouped according to positiveness or negativeness of the category and the topic. The resulting distribution is given in Table 3.

Examining the distribution of codes according to categories as shown in Table 3, it is seen that the negative codes were the majority in most categories expect for $\mathrm{C} 1, \mathrm{C} 2$ and $\mathrm{C} 5$. Examining the distribution of topics on the other hand, the positive codes were in the majority for Photoelectric Effect, Atomic Spectra and Wave Properties of Particles topics and the negative codes were in the majority for the other topics.

$\mathrm{C} 1$, the category with the highest number of positive codes, was in the second place in terms of total number of codes. Most of the positive codes in the $\mathrm{C} 1$ category were codes emphasizing the ease of using formulas and solving problems. Negative codes were related to difficulties with formulas and problems. The positive codes in this category were 
concentrated in the Photoelectric Effect, Atomic Spectra, Wave Properties of Particles and the Uncertainly Principle topics; the number of positive codes was higher compared to the negative codes. However, the number of negative codes was significantly higher compared to the positive codes in the Compton Effect topic. In the Black Body Radiation and Bohr's Atom Model topics, the numbers of positive and negative codes were fairly similar. On the other hand, there were no codes for the Double-slit Experiment with Electrons topic. This might be due to the fact that the Double-slit Experiment with Electrons topic doesn't involve mathematical expressions, but instead, it is taught based on interpretation. In participant statements related to the Wave Properties of Particles topic, it was emphasized that formulas were easy. Regarding the other topics in $\mathrm{C} 1$ which had a high number of positive codes, statements related to the ease of using formulas and solving problems had the majority. Participant A21's remark of ".. being able to solve the problems using a single formula provides great convenience," regarding the Photoelectric Effect topic is a good example. The cause of difficulty for the Compton Effect topic, in which negative opinions had the majority, was stated to be significant difficulties related to find and use formulas, and it was also expressed that it was difficult to memorize the formulas and the formulas seemed complicated. For example, A23's remark of "... the possibility of making a mistake is higher because operations are very long." was mentioned as a cause of difficulty in the Compton Effect topic. Regarding the Bohr's Atom Model topic, in which negative opinions were more common, although formulas were considered to be difficult, problems were described as easy.

Table 3. The Distribution of the code frequency according to topics and categories

\begin{tabular}{|c|c|c|c|c|c|c|c|c|c|c|}
\hline Topics & $\begin{array}{l}\text { Positive } \\
\text { Negative }\end{array}$ & $\mathrm{C} 1$ & $\mathrm{C} 2$ & $\mathrm{C} 3$ & $\mathrm{C} 4$ & $\mathrm{C} 5$ & C6 & $\mathrm{C} 7$ & $\mathrm{C} 8$ & Total \\
\hline \multirow[b]{2}{*}{ Black Body Radiation } & Positive & 11 & 2 & 0 & 6 & 0 & 9 & 0 & 4 & 32 \\
\hline & Negative & 12 & 2 & 2 & 11 & 0 & 19 & 1 & 1 & 48 \\
\hline \multirow{2}{*}{ Photoelectric Effect } & Positive & 18 & 4 & 1 & 0 & 1 & 11 & 0 & 1 & 36 \\
\hline & Negative & 9 & 1 & 0 & 1 & 0 & 17 & 0 & 0 & 28 \\
\hline \multirow{2}{*}{ Compton Effect } & Positive & 14 & 2 & 0 & 0 & 0 & 8 & 0 & 0 & 24 \\
\hline & Negative & 21 & 0 & 1 & 0 & 1 & 13 & 1 & 0 & 37 \\
\hline \multirow{2}{*}{ Atomic Spectra } & Positive & 5 & 19 & 0 & 0 & 1 & 10 & 0 & 1 & 36 \\
\hline & Negative & 0 & 1 & 5 & 0 & 0 & 13 & 2 & 1 & 22 \\
\hline \multirow{2}{*}{ Bohr's Atom Model } & Positive & 13 & 2 & 0 & 0 & 1 & 8 & 0 & 0 & 24 \\
\hline & Negative & 16 & 1 & 0 & 1 & 0 & 21 & 0 & 1 & 40 \\
\hline \multirow{2}{*}{$\begin{array}{l}\text { Wave and Particle Properties } \\
\text { of Light }\end{array}$} & Positive & 0 & 10 & 0 & 5 & 0 & 2 & 0 & 6 & 23 \\
\hline & Negative & 2 & 1 & 2 & 10 & 0 & 4 & 3 & 5 & 27 \\
\hline \multirow{2}{*}{ Wave Properties of Particles } & Positive & 10 & 2 & 8 & 2 & 5 & 5 & 0 & 0 & 32 \\
\hline & Negative & 1 & 0 & 1 & 2 & 0 & 5 & 1 & 7 & 17 \\
\hline \multirow{2}{*}{$\begin{array}{l}\text { Double-slit Experiment with } \\
\text { Electrons }\end{array}$} & Positive & 0 & 10 & 1 & 4 & 2 & 2 & 0 & 0 & 19 \\
\hline & Negative & 0 & 1 & 1 & 5 & 0 & 15 & 1 & 7 & 30 \\
\hline \multirow{2}{*}{ Uncertainly Principle } & Positive & 21 & 7 & 1 & 5 & 0 & 0 & 0 & 0 & 34 \\
\hline & Negative & 6 & 1 & 5 & 11 & 0 & 14 & 1 & 0 & 38 \\
\hline \multirow{2}{*}{ Total } & Positive & 92 & 58 & 11 & 22 & 10 & 55 & 0 & 12 & 260 \\
\hline & Negative & 67 & 8 & 17 & 41 & 1 & 121 & 10 & 22 & 287 \\
\hline
\end{tabular}

The vast majority of codes in the $\mathrm{C} 2$ category containing method-related codes were positive. Based on this fact, it can be said that there was no significant problem regarding the method. The positive codes appeared to be dominant especially in the Atomic Spectra, Wave and Particle Properties of Light, Double-slit Experiment with Electrons and the Uncertainly Principle topics. The majority of codes in the Atomic Spectra topic were related to usefulness of the experiment demonstrating the line spectrum belonging to certain rarefied gases. The positive codes in the Double-slit Experiment with Electrons topic in particular, emphasized the usefulness of the animation screening during class. A15's remark of "It is hard to understand the behaviour of electrons that are impossible to observe, but I was able to understand the topic thanks to the animation that we watched during class", shows the usefulness of the animation. It can be said regarding the few negative codes that the difficulties were experienced due to the intensity of verbal instruction and topics being impossible to observe in everyday life.

Most of the codes were negative in $\mathrm{C} 3$, which had a relatively low number of codes compared to $\mathrm{C} 1$ and $\mathrm{C} 2$ in total. On the other hand, the high number of positive codes in the Wave Properties of Particle topic is noteworthy. It can be said that a large part of positive codes in this category was in the Wave Properties of Particles topic. This is due to the fact that students accepted the wave property of particles easily. Some students claimed that it was easier to understand this concept after studying the Double-slit Experiment with Electrons topic. A19's remark of "I easily accepted the wave feature of particles because it was explained in double slit experiments with electrons (the topic after Wave Properties of Particle)" can be given as an example. The negative codes concentrated in the Atomic Spectra and the Uncertainly Principle topics. It can be said that the negative codes were generally due to examination and grade anxiety, as well as bias towards the topic or disregarding the topic. For example, with his remark of "Actually, I had thought that this topic (Atom Spectrums) was easy. But I started to think that the topic was hard when I wasn't able to answer the questions 
related to the topic in exams", A10 stated that his thoughts about the topic changed due to the problems that he experienced in examinations.

It can be said that the number of negative codes in the $\mathrm{C} 4$ category were probably due to difficulties related to the transition from classical physics to quantum physics. The negative codes in question were evident in the Black Body Radiation topic, which is an introduction to quantum physics, in the Wave and Particle Properties of Light topic, which deals with the dual character of the light for the first time, and in the Uncertainly Principle topic, in which the change in the measurement system is explained. The reason why negative codes were concentrated in these topics might be that these are the first topics that introduce a new understanding. The relatively small number of positive codes, on the other hand, suggests the opposite of negative codes. For example, while there were those who had difficulties in accepting the wave and particle characters of light at the same time, there were also those who claimed that it was easy.

The C5 category, which contains the relationship between the quantum physics topics, had quite a low number of codes and almost all of these were positive. Half of these positive codes were in the Wave Properties of Particles topic. Regarding these positive codes in the Wave Properties of Particles topic, the participants stated that it was easy to understand this topic since they had already understood the dual nature of the light. Having understood the Wave Properties of Particles topic, it was easier to understand the Double-slit Experiment with Electrons topic. For example, A19's remark of "I better understood this topic (Double-slit Experiment with Electrons) after the previous two topics (Wave and Particle Properties of Light and Wave Properties of Particles)", emphasizes this situation. The same participant had shown a similar approach by referring to the Double-slit Experiment with Electrons topic in his comment given above regarding the Wave Properties of Particles topic (in C3 category). This can be interpreted as that the Wave and Particle Properties of Light, Wave Properties of Particles and Double-slit Experiment with Electrons are topics that support each other.

The negative codes were significantly dominant in topics of the C6 category, which had the highest number of codes, except for the Wave Properties of Particle topic. Negative codes usually concentrated on difficulties related to requiring effort studying and extra time to understand the topics. Positive codes, on the other hand, were those indicating that the topics were easy to understand after studying. A7 explained this situation with his remark of "It (Photoelectric Effect) is easy once you understand the how it functions, but it takes effort and studying."

All of the codes in the $\mathrm{C} 7$ category, which had a relatively smaller number of codes, were negative and almost all of these negative codes in question were related to difficulties to understanding the topic abstractly. For example, A5 explained the negative effects of abstractness of the topics with the remark of "It is hard to understand wave feature of particles" and A21 with his remark of "The experiments (regarding Wave and Particle Properties of Light) were successful in demonstrating the wave-particle character of the light. However, I was confused about when it shows wave character and when it shows particle character because these are abstract concepts."

The Wave Properties of Particles and the Double-slit Experiment with Electrons topics in particular and the Wave and Particle Properties of Light topic to some degree constituted the majority of negative codes in $\mathrm{C} 8$, in which negative codes were dominant in general. However, the Wave and Particle Properties of Light topic, together with the Black Body Radiation topic, made up the majority of positive codes as well. Most of the negative codes were related to the dual character of light. In addition, the codes related to difficulty in imagining a particle without mass (photon) were noteworthy. Positive codes, on the other hand, concentrated on the fact that the Black Body Radiation topic is considered to be a basic topic in quantum physics as well as the importance of Planck's constant.

\section{Discussion}

An examination of the data obtained as a result of the study reveals that the biggest difficulty experienced by the participants was related to its requiring extra effort studying and time to understand the topics. Some of the students stated that they had failed the quantum physics course before and had to repeat the course. A similar case was found in another study as well. The students expressed that they repeated the course and felt uncomfortable with the concepts of quantum physics (Akarsu, Coşkun \& Kariper, 2011). This can be interpreted as that failure in quantum physics is a common problem. However, as concluded from positive opinions, the participants believed that the concepts were easy to understand with sufficient effort and time.

There is a concentration in opinions of the participants about the difficulties with mathematics used in quantum physics. Most of these opinions were positive. However, there was a considerable amount of negative opinions as well. Some studies point out that the concepts of quantum physics can be taught without dealing with mathematical difficulties (Rebello \& Zollman, 1999; Zollman et. al, 2002). Taking into account that there was a considerable amount of negative opinions as well, it might be beneficial to refer to mathematics less often, since it will reduce the number of difficulties experienced in quantum physics courses. 
It is thought that there were no method-related difficulties experienced by the participants when learning the topics in question. It was emphasized by the participants that using visualizations, animations, experiments and similar methods gave positive results and facilitated understanding of the subject. According to Abhang (2005), rather than solely depending on theoretical ideas, the quantum physics topics should be discussed in light of experiments and thought experiments must be used effectively. Additionally, it was mentioned by some of the participants that following a chronological order when teaching the concepts had a positive effect. The fact that especially the development of the atomic theory is explained in textbooks by following a chronological order is compatible with the teaching of the history and philosophy of science as well (Niaz, 1998; Niaz and Rodriguez, 2001). Creating science-literate individuals is one of the important goals of science education. Science education experts state that teaching the nature of science is necessary to reach this goal (Abd-El-Khalick, \& Lederman, 2000; Backhus \& Thompson, 2006; Doğan-Bora, Arslan \& Çakıroğlu, 2006; Lederman \& Zeidler, 1987). Using this approach when teaching other subjects as well will be beneficial for a better understanding of quantum physics. Also, the fact that the participants stated that they had no problems with associating quantum physics topics with each other supports this idea. Although there are lots of positive opinions, the small number of negative opinions indicates that the intensity of verbal instruction causes problems. The intensity of verbal instruction might have caused the students to get bored. Also, the fact that the participants believed they could not observe examples of the concepts in question in everyday life was another problem.

It is seen that the students had significant difficulties with topics such as Black Body Radiation, which is an introduction to quantum physics, in the Wave and Particle Properties of Light topic, which deals with the dual character of the light for the first time, and in the Uncertainly Principle topic, in which the change in the measurement system is explained. In this case, problems might have caused by leaving classical physics behind and adopting a new understanding. According to Ireson (1999), wave-particle duality is the cornerstone of the understanding of quantum events. In some studies, it was discussed that classical physics led to problems in the teaching of quantum physics (Ireson, 1999; Kalkanis, Hadzidaki \& Stavrou 2003; Şen, 2002; Thacker, 2003). Although the real-world is quantum mechanical, students' world view is classical mechanical; concepts of quantum physics and classical physics overlap and mix-up (Kalkanis et al., 2003). The fact that it is possible to identify all physical properties of a system in classical physics causes problems for students in introductory quantum physics courses (Baily \& Finkelstein, 2009). In addition, Steinberg et al. (1996) report that difficulties related to concepts of classical physics had negative effects on learning the concepts of quantum physics. Although students are aware of the fact that there is a need for a model that deals with microscopic particles and processes, they base these models on classical physics (Thacher, 2003). Levrini and Fantini (2013) argue that using historical debates when teaching quantum physics will facilitate the transition from classical physics to quantum physics.

The participants emphasized that the topics had an abstract nature. Problems arising from the abstract nature of concepts are common in other physics topics as well (Chen \& Gladding, 2014; Podolefsky \& Finkelstein, 2007). Accordingly, it was observed in this study that this had negative effects in terms of both teaching and, from the participants' point of view, learning the concepts of the topic. The fact that the participants encountered some of the concepts related to quantum physics for the first time might have enhanced this effect. Lastly, the participants expressed opinions indicating that they had prejudices related to examination and grade anxiety and the difficulty of the course. This might have affected the negative attitude of the participants towards introductory quantum physics topics. In order to better understand the difficulties experienced in this regard, it would be beneficial to research attitudes of students towards the quantum physics.

This research should also be done with pre-service physics teachers of other universities. The different views obtained in this way can reveal the difficulties encountered in learning quantum physics from a different perspective. Since this research is a qualitative research, its results cannot be generalized to the population. However, the analytic generalization made will help to understand the nature of the difficulties. If quantitative scale is formed by regulating the difficulties of learning the quantum physics, more number of pre-service teachers can be reached. Thus, generalizable results can be obtained.

\section{References}

Abd-El-Khalick, F., \& Lederman, N. G. (2000). Improving science teachers' conceptions of nature of science: A critical review of the literature. International Journal of Science Education, 22(7), 665-701. https://doi.org/10.1080/09500690050044044

Abhang, R. Y. (2005). Making introductory quantum physics understandable and interesting. Resonance Journal of Science Education, 10(1), 63-73. https://doi.org/10.1007/bf02835894

Akarsu, B., Coşkun, H., \& Kariper, İ. A. (2011). An investigation on college students' conceptual understanding of quantum physics topics. Mustafa Kemal University Journal of Social Sciences Institute, 8(15), 349-362. 
Altunışık, R., Coşkun, R., Yıldırım, E., \& Bayraktaroğlu, S. (2002). Research Methods in Social Sciences (2nd Edition). Adapazarı: Sakarya Publishing.

Angell, C., Guttersrud, Ø., Henriksen, E. K., \& Isnes, A. (2004). Physics: Frightful, but fun. Pupils' and teachers' views of physics and physics teaching. Science Education, 88, 683-706. https://doi.org/10.1002/sce.10141

Aslan, O. (2009). The opinions of science and technology teachers about the nature of science and their reflections on classroom practices. Unpublished PhD Disseration, Gazi University Institute of Educational Sciences. Ankara.

Ayene, M., Kriek, J., \& Damtie, B. (2011). Wave-particle duality and uncertainty principle: Phenomenographic categories of description of tertiary physics students' depictions. Physical Review Special Topics-Physics Education Research, 7. https://doi.org/10.1103/PhysRevSTPER.7.020113

Backhus, D. A., \& Thompson, K. W. (2006). Addressing the nature of science in preservice science teacher preparation programs: Science educator perceptions. Journal of Science Teacher Education, 17, 65-81. https://doi.org/10.1007/s10972-006-9012-9

Baily, C., \& Finkelstein, N. D. (2009). Development of quantum perspectives in modern physics. Physical Review Special Topics-Physics Education Research, 5. https://doi.org/10.1103/PhysRevSTPER.5.010106

Baybars, M. G., \& Küçüközer, H. (2014). The pre-service science teachers' conceptual understanding of quantum physics. Muğla Sitkı Koçman University Journal of Education, 1(1).

Bayı, F. (2010). Interactions between internal representations and external representations generated by 11. Class secondary students' related with geometric problems. Unpublished Master's Thesis, Gazi University Institute of Educational Sciences. Ankara.

Chen, Z., \& Gladding, G. (2014). How to make a good animation: A grounded cognition model of how visual representation design affects the construction of abstract physics knowledge. Physical Review Special Topics-Physics Education Research, 10. https://doi.org/10.1103/PhysRevSTPER.10.010111

De Leone, C. J., \& Oberem, G. E. (2004). Toward understanding student conceptions of the photoelectric effect. AIP Conference Proceedings, 720, 85. https://doi.org/10.1063/1.1807260

Didiş, N., Özcan, Ö., \& Abak, M. (2008). Quantum physics from students' perspective: A qualitative study. Hacettepe University Journal of Education, 34, 86-94.

Doğan-Bora, N., Arslan, O., \& Çakıroğlu, J. (2006). What do high school students think about science and scientists? Hacettepe University Journal of Education, 31, 32-44.

Fletcher, P., \& Johnston, I. (1999). Quantum mechanics: exploring conceptual change. Paper presented at the annual meeting National Association for Research in Science Teaching.

Henriksen, E. K, Berit, B. B., Angell, C., Tellefsen, C. W., Frågåt, T., \& Bøe, M. V. (2014). Relativity, quantum physics and philosophy in the upper secondary curriculum: challenges, opportunities and proposed approaches. Physics Education, 49(6), 678-684. https://doi.org/10.1088/0031-9120/49/6/678

Ireson, G. (1999). A multivariate analysis of undergraduate physics students' conceptions of quantum phenomena. European Journal of Physics, 20, 193-199. https://doi.org/10.1088/0143-0807/20/3/309

Johansson, K. E., \& Milstead, D. (2008). Uncertainty in the classroom-teaching quantum physics. Physics Education, 43(2), 173-179. https://doi.org/10.1088/0031-9120/43/2/006

Kalkanis, G., Hadzidaki, P., \& Stavrou, D. (2003). An instructional model for a radical conceptual change towards quantum mechanics concepts. Science Education, 87, 257-280. https://doi.org/10.1002/sce.10033

Kızılcık, H. Ş., Daml, V., \& Ünsal, Y. (2014). Physics in movies: Awareness levels of teacher candidates. Eurasia Journal of Mathematics Science \& Technology Education, 10(6), 681-690.

Lederman, N. G., \& Zeidler, D. L. (1987). Science teachers' conceptions of the nature of science: Do they really influence teaching behavior? Science Education, 71(5), 721-734. https://doi.org/10.1002/sce.3730710509

Levrini, O., \& Fantini, P. (2013). Encountering productive forms of complexity in learning modern physics. Science \& Education, 22, 1895-1910. https://doi.org/10.1007/s11191-013-9587-4

Lincoln, Y. S., \& Guba, E. G. (1985). Naturalistic inquiry. Beverly Hills, CA: Sage.

Manilla, K., Koponen, I. T., \& Niskanen, J. A. (2002). Building a picture of students' conceptions of wave- and particle-like properties of quantum entities. European Journal of Physics, 23, 45-53. https://doi.org/10.1088/0143-0807/23/1/307 
McDermott, L. C., \& Redish, E. F. (1999). Resource letter: PER-1: Physics education research. American Journal of Physics, 67, 755. https://doi.org/10.1119/1.19122

Merriam, S. B. (1998). Qualitative research case study applications in education. San Francisco, CA: Jossey-Bass Publishers.

Müller, R., \& Wiesner, H. (2002). Teaching quantum mechanics on an introductory level. American Journal of Physics, 70, 200. https://doi.org/10.1119/1.1435346

Niaz, M. (1998). From cathode rays to alpha particles to quantum of action: A rational reconstruction of structure of the atom and its implications for chemistry textbooks. Science Education, 82, 527-552. https://doi.org/10.1002/(SICI)1098-237X(199809)82:5<527::AID-SCE1>3.0.CO;2-B

Niaz, M., \& Rodriguez, M. A. (2001). Do we have to introduce history and philosophy of science or is it already 'inside' chemistry? Chemistry Education Research and Practice, 2(2), 159-164. https://doi.org/10.1039/B1RP90015C

Ornek, F., Robinson, W. R., \& Haugan, M. P. (2007). What makes physics difficult? Science Education International, 18(3), 165-172.

Özdemir, E., \& Erol, M. (2011). Uncertainty principle of quantum physics: Effects of hybrid teaching on academic achievement and retention. Journal of Buca Education Faculty, Dergisi, 29, 20-35.

Podolefsky, N. S., \& Finkelstein, N. D. (2007). Analogical scaffolding and the learning of abstract ideas in physics: An example from electromagnetic waves. Physical Review Special Topics-Physics Education Research, 3. https://doi.org/10.1103/physrevstper.3.010109

Pospiech, G. (2000). Uncertainty and complementarity: The heart of quantum physics. Physics Education, 35(6), 393-399. https://doi.org/10.1088/0031-9120/35/6/303

Rebello, N. S., \& Zollman, D. (1999). Conceptual understanding of quantum mechanics after using hands-on and visualization instructional materials. Papers presented at the annual meeting National Association for Research in Science Teaching.

Şahin, E., \& Yağbasan, R. (2012). Determining which introductory physics topics pre-service physics teachers have difficulty understanding and what accounts for these difficulties. European Journal of Physics, 33, 315-325. https://doi.org/10.1088/0143-0807/33/2/315

Şen, A. İ. (2002). The evaluation of fundemantal concepts and events of quantum physics by pre-service physics teachers. Journal of Ballkesir University Institude of Science and Tecnology, 4, 76-85.

Singh, C. (2008). Interactive learning tutorials on quantum mechanics. American Journal of Physics, 76(4), 400-405. https://doi.org/10.1119/1.2825387

Steinberg, R. N., Oberem, G. E., \& McDermott, L. C. (1996). Development of a computer - based tutorial on the photoelectric effect. American Journal of Physics, 64, 1370. https://doi.org/10.1119/1.18360

Strauss, A. L., \& Corbin, J. (1990). Basics of qualitative research: Grounded theory procedures and techniques. Newbury Park, CA: Sage Publications.

Thacker, B. A. (2003). A study of the nature of students' models of microscopic processes in the context of modern physics experiments. American Journal of Physics, 71, 599. https://doi.org/10.1119/1.1566431

Yıldırım, A., \& Şimşek, H. (2006). Qualitative research methods in the social sciences. 5th Edition, Ankara: Seçkin Publishing.

Yıldız, A., \& Büyükkasap, E. (2011). Understanding levels of pre-service teachers about the uncertainty principle and academic achievement effect of writing with learning purpose. Journal of Turkish Science Education, 8(4).

Yin, R. Y. (1984). Case study research. Design and methods. Second Edition. Thousand Oaks, CA: Sage Publication.

Zollman, D. A., Rebello, S., \& Hogg, K. (2002). Quantum mechanics for everyone: Hands-on activities integrated with technology. American Journal of Physics, 70, 252. https://doi.org/10.1119/1.1435347

\section{Copyrights}

Copyright for this article is retained by the author(s), with first publication rights granted to the journal.

This is an open-access article distributed under the terms and conditions of the Creative Commons Attribution license which permits unrestricted use, distribution, and reproduction in any medium, provided the original work is properly cited. 